\title{
Persistent Lagrangian Transport Patterns in the Northwestern Gulf of Mexico
}

\author{
Matt K. Gough, ${ }^{\mathrm{a}}$ Francisco J. Beron-Vera, ${ }^{\mathrm{b}}$ María J. Olascoaga, ${ }^{\mathrm{c}}$ Julio Sheinbaum, ${ }^{\mathrm{a}}$ \\ JULIEN JOUANNO, ${ }^{\mathrm{d}}$ AND RODRIGO DURAN ${ }^{\mathrm{e}}$

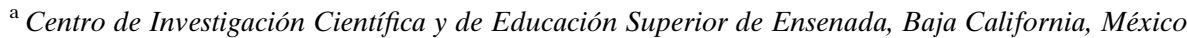 \\ ${ }^{\mathrm{b}}$ Department of Atmospheric Sciences, Rosenstiel School of Marine and Atmospheric Science, University of Miami, Miami, Florida \\ ${ }^{\mathrm{c}}$ Department of Ocean Sciences, Rosenstiel School of Marine and Atmospheric Science, University of Miami, Miami, Florida \\ d Laboratoire d'Etudes en Géophysique et Océanographie Spatiales, Toulouse, France \\ ${ }^{\mathrm{e}}$ College of Earth, Ocean and Atmospheric Sciences, Oregon State University, Corvallis, Oregon
}

(Manuscript received 11 October 2017, in final form 18 November 2018)

\begin{abstract}
Persistent Lagrangian transport patterns at the ocean surface are revealed from climatological Lagrangian coherent structures (cLCSs) computed from daily climatological surface current velocities in the northwestern Gulf of Mexico (NWGoM). The climatological currents are computed from daily velocities produced by an 18-yr-long free-running submesoscale-permitting Nucleus for European Modelling of the Ocean (NEMO) simulation of the Gulf of Mexico. Despite the intense submesoscale variability produced by the model along the shelf break, which is found to be consistent with observations and previous studies, a persistent mesoscale attracting barrier between the NWGoM shelf and the deep ocean is effectively identified by a hook-like pattern associated with persistent strongly attracting cLCSs. Simulated tracer and satellitetracked drifters originating over the shelf tend to be trapped there by the hook-like pattern as they spread cyclonically. Tracers and drifters originating beyond the shelf tend to be initially attracted to the hook-like pattern as they spread anticyclonically and eventually over the deep ocean. The findings have important implications for the mitigation of contaminant accidents such as oil spills.
\end{abstract}

\section{Introduction}

There are thousands of oil platforms and oil exploration sites in the northwestern Gulf of Mexico (NWGoM). Oil exploration and drilling are expected to continue, particularly since the Mexican national oil company made a major discovery in the Perdido fold belt in 2012. The Perdido fold belt is a geological formation that encompasses an area of nearly $40000 \mathrm{~km}^{2}$ across the maritime border between the United States and Mexico, lies off the continental slope at a depth of approximately $2500 \mathrm{~m}$, and is rich in crude oil and natural gas. On the U.S. side of this rich oil-gas reservoir, international oil companies are already producing oil and planning expansions. Understanding surface material transport in this region is therefore critical for oil spill response and mitigation.

The surface circulation in the NWGoM is dominated by the northern extent of a persistent western boundary current that flows anticyclonically along the continental shelf break demarked by the $50-\mathrm{m}$ isobath (Figs. 1,2).

Corresponding author: Matt K. Gough, mkgough@nps.edu
The western boundary current, largely driven by wind stress, exhibits seasonal variability with the strongest currents observed in summer and weakest currents observed in the fall (Oey 1995; Sturges 1993). Additional variability in the western boundary current is provided by interaction with eddies that have been shed off the Loop Current and propagate toward the NWGoM (Sutyrin et al. 2003; Vukovich and Crissman 1986). The highly energetic Loop Current eddies range in size from 100 to $300 \mathrm{~km}$ in diameter, are generated every 3-17 months, and introduce circulation variability in the NWGoM until they eventually dissipate after interacting with the continental shelf (Hall and Leben 2016; Hamilton et al. 1999, 2002; Leben 2005; Sturges and Leben 2000). There is an abrupt change in circulation characteristics shoreward of the western boundary current over the NWGoM continental shelf, which includes the broad Louisiana-Texas (LaTex) shelf and relatively narrow Mexico-Texas (MexTex) shelf. Flow over the NWGoM shelf is relatively weak, generally cyclonic, and predominantly driven by the along-shelf component of the wind stress (Chu et al. 2005; Oey 1995; Ohlmann and Niiler 2005; Zavala-Hidalgo et al. 2003). 


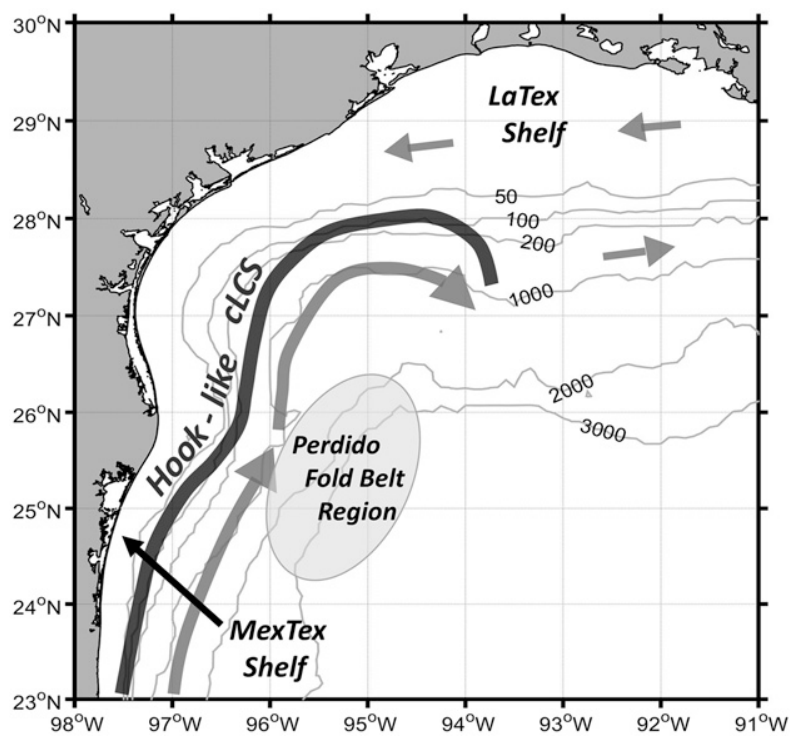

FIG. 1. Location map of the NWGoM. Gray arrows indicate general flow patterns over the shelf and along the shelf break. The thick black line demarks the general position of the persistent hook-like cLCS.

Additional forcing that contributes to the cyclonic flow is provided by buoyancy plume behavior of the Mississippi-Atchafalaya River system discharge and, to a smaller extent, Loop Current eddies impinging upon the shelf (Oey 1995). Seasonal variability in the flow is therefore influenced by the seasonal variability in wind forcing, discharge from the MississippiAtchafalaya River system, and Loop Current eddy impingement. Winds are predominantly from the west in the spring and fall, from the southeast in the summer, and from the northeast in the winter (Morey et al. 2005; Zavala-Hidalgo et al. 2003). Freshwater discharge peaks in the late spring and reaches a minimum in late fall. The resulting mean flow over the NWGoM shelf is cyclonic during the spring, winter, and fall, with the strongest westward flow over the LaTex shelf occurring during the spring and fall when winds are from the east. Winds from the southeast during the summer drive anticyclonic flow along the MexTex shelf while flow along the LaTex shelf is weak owing to a small alongshore wind stress component. A salinity front typically occurs along the outer shelf demarking the boundary between semifreshwater discharge over the shelf and resident Gulf of Mexico (GoM) water beyond the shelf break. During the summer the front typically resides along the LaTex shelf break and partially extends along the MexTex shelf (Zavala-Hidalgo et al. 2003). During the winter the front migrates shoreward over the LaTex shelf and extends farther south along the MexTex shelf. The front is observed to persist despite the strong submesoscale activity seen in numerical simulations (Luo et al. 2016).

The goal of this paper is to make use of the theory of Lagrangian coherent structures (LCSs) (Haller 2015), which is derived from nonlinear dynamical systems techniques, to extract persistent Lagrangian transport trends from a long (18 year) submesoscale-permitting model simulation. The LCSs are key material lines (i.e., transport barriers) that influence neighboring fluid and shape global transport and mixing. The challenge here is how to meaningfully process the information contained in such a large dataset. Lagrangian trajectory integrations require repetitive interpolation of the flow data which can be computationally expensive. This cost is compounded when these computations are repeated to illuminate general trends in Lagrangian transport. LCS studies therefore typically focus on case studies or scenarios which verify observations with LCS maps (e.g., comparisons of LCS maps to satellite imagery of chlorophyll concentrations, sea surface temperature, or oil spill observations; Gough et al. 2016; Olascoaga and Haller 2012; Olascoaga et al. 2013). Recently, climatological LCSs, or cLCSs, computed from a numerical model simulation have been shown to effectively identify persistent surface transport patterns (Duran et al. 2018). Here we follow Duran et al. (2018) by extracting cLCSs from daily climatological surface current velocities constructed from a multiyear model simulation. There are two primary objectives to this study: 1) to provide a guideline for interpreting the cLCSs and 2) to provide maps of persistent sea surface Lagrangian transport patterns in the NWGoM. The maps can be applied as a guideline for predicting pollution transport at the ocean surface.

\section{Methods}

\section{a. Model}

This study incorporates an 18-yr (1995-2012) numerical simulation of daily surface current velocities over the NWGoM. The simulation was performed with the Nucleus for European Modelling of the Ocean (NEMO) primitive-equation modeling framework (Madec and the NEMO Team 2016). The model is three-dimensional, utilizes curvilinear coordinates discretized on a $\mathrm{C}$ grid, has 75 fixed vertical levels (12 levels in the upper $20 \mathrm{~m}$ and 24 levels in the upper $100 \mathrm{~m}$ ), has a horizontal resolution of $1 / 36^{\circ}$ (approximately $2.8 \mathrm{~km}$ ), has a time step of $150 \mathrm{~s}$, and encompasses the entire GoM between latitudes $14^{\circ}$ and $31^{\circ} \mathrm{N}$ and longitudes $98^{\circ}$ and $78^{\circ} \mathrm{W}$. Surface current velocities were taken from the top level (1-m depth). Forcing at the lateral boundaries was provided by the daily Mercator global ocean reanalysis GLORYS2V3. 

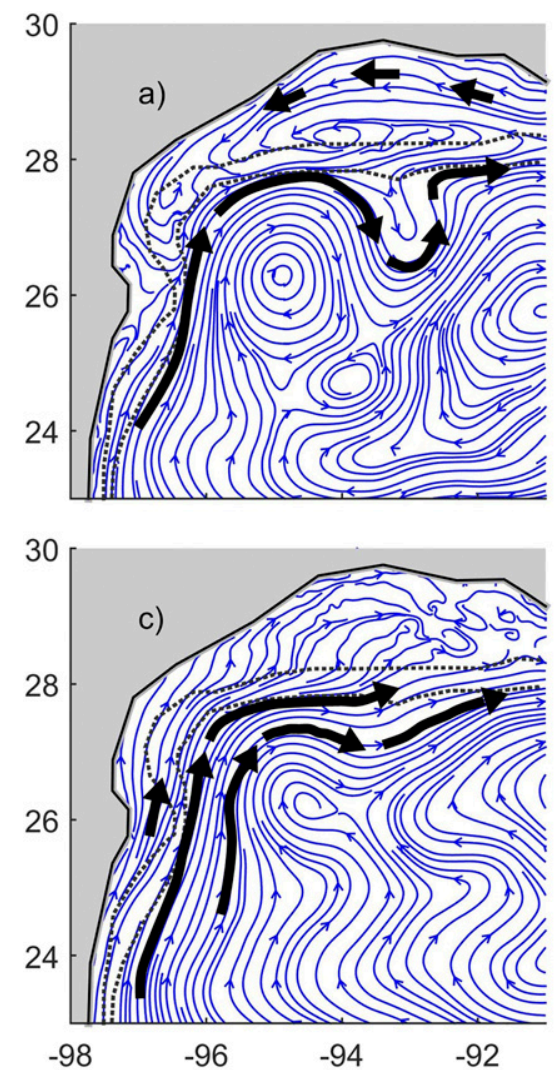
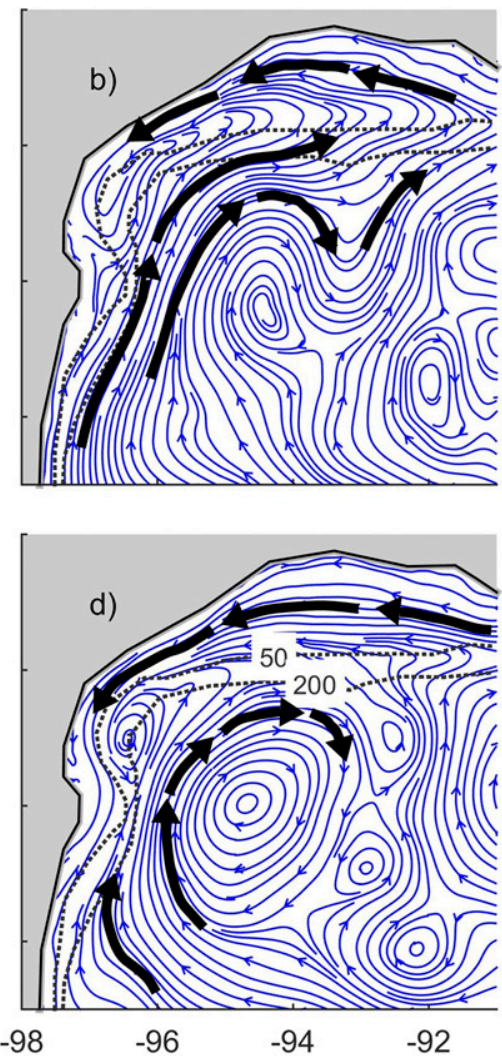

FIG. 2. Monthly climatological streamlines (blue) for (a) January, (b) April, (c) July, and (d) October. Black arrows demark notable flow patterns. The 50- and 200-m isobaths are demarked by the black dashed lines and are labeled in (d).

Additionally, the model was forced at the surface with the Drakkar Forcing Sets version 5.2 (DFS5.2; Dussin et al. 2016). DFS5.2 consists of 3-h fields of wind, temperature, and humidity, and daily fields of radiation (longwave and shortwave) and precipitation. Freshwater discharge incorporated by the model was based on monthly runoff climatology (Dai and Trenberth 2002). The simulation was initialized using geostrophic balance and the temperature and salinity fields obtained from $1 / 4^{\circ}$ outputs of Mercator GLORYS2V3 reanalysis at day 1 January 1993 and then integrated over a 20-yr period (1993-2012). The first 2 years were neglected to allow for spinup. Daily outputs were generated from the original data. This regional model configuration has been used in Jouanno et al. (2016) to study the formation of short-period Loop Current frontal eddies. We refer the reader to this publication for further details on the numerical configuration and a validation of the background state (currents and eddy kinetic energy) as well as detailed comparisons of the eddy properties in the Loop Current area with in situ and satellite observations. The model allows a partial range of submesoscale processes since these processes occur at scales $O(100) \mathrm{m}$ to $O(10) \mathrm{km}$.
Because the surface mixed layer depth varies seasonally, there may be a seasonal bias in the model's ability to resolve submesoscale processes, which may not be possible to be eliminated by increasing the model's resolution without degrading its skill at the mesoscale (Sandery and Sakov 2017).

\section{b. Lagrangian coherent structures}

It is now well accepted that underlying fluid flow is a Lagrangian entity that can be said to be responsible for shaping the transport and mixing of passive tracers into organized patterns. The building blocks of such a Lagrangian skeleton are robust fluid surfaces, widely called Lagrangian coherent structures (Haller 2015).

LCS analysis begins with the motion equation for fluid particles,

$$
\frac{d x}{d t}=v(x, t)
$$

where $v(x, t)$ is the two-dimensional velocity of the fluid, with $x=\left(x^{1}, x^{2}\right)$ denoting position in some domain of $\mathbb{R}^{2}$ and $t$ time within a finite interval of $\mathbb{R}$. If $v(x, t)$ is smooth, 
solving this equation for fluid particles at positions $x_{0}$ at $t_{0}$, one obtains a smooth map with smooth inverse that takes these positions to positions $x$ at another $t$, namely,

$$
F_{t_{0}}^{t}\left(x_{0}\right):=x\left(t ; x_{0}, t_{0}\right)
$$

A fundamental observer-independent (or objective) measure of local (i.e., pointwise) fluid deformation is given by the (right) Cauchy-Green strain tensor, whose associated matrix is given by

$$
C_{t_{0}}^{t}\left(x_{0}\right):=\partial_{x_{0}} F_{t_{0}}^{t}\left(x_{0}\right)^{\mathrm{T}} \partial_{x_{0}} F_{t_{0}}^{t}\left(x_{0}\right) .
$$

Here $\partial_{x_{0}} F_{t_{0}}^{t}\left(x_{0}\right) \in \mathbb{R}^{2}$ is the (normalized) fundamental matrix solution of the variational equation $\dot{y}=$ $\left.\partial_{x} v(x, t)\right|_{x=F_{t_{0}}\left(x_{0}\right) y}$ for a small perturbation $y\left(t ; y_{0}, t_{0}\right)$ to a trajectory $x\left(t ; x_{0}, t_{0}\right)$ of $(1)$. Note that $C_{t_{0}}^{t}\left(x_{0}\right)$ is symmetric by construction and furthermore positive definite owing to invertibility of $\partial_{x_{0}} F_{t_{0}}^{t}\left(x_{0}\right)$. As a consequence, its eigenvalues and eigenvectors satisfy $0<\lambda_{1}\left(x_{0}\right) \leq \lambda_{2}\left(x_{0}\right)$ and $\xi_{1}\left(x_{0}\right) \perp \xi_{2}\left(x_{0}\right)$, respectively.

The geodesic theory of LCSs seeks LCSs as extremum curves of global (i.e., curve integrated) absolute deformation (Haller and Beron-Vera 2012) or stationary curves of global relative deformation (Farazmand et al. 2014). The boundary conditions arising in these variational principles indicate that a hyperbolic LCS at time $t_{0}$ that attracts neighboring fluid from $t_{0}-T$ through $t_{0}(T>0)$ is a material curve $x_{0}(s)$ such that

$$
\frac{d x_{0}}{d s}=\xi_{1}\left(x_{0}\right),
$$

where $\xi_{1}\left(x_{0}\right)$ is tangent to $x_{0}(s)$ and along which

$$
\frac{1}{\sqrt{\xi_{2}\left(x_{0}\right) C_{t_{0}}^{t}\left(x_{0}\right)^{-1} \xi_{2}\left(x_{0}\right)}}=\sqrt{\lambda_{2}\left(x_{0}\right)}>1,
$$

which measures attraction normal to the curve (Haller 2011). Condition (5) is immediately satisfied when the flow is incompressible [since in that case $\operatorname{det} C_{t_{0}}^{t}\left(x_{0}\right)=$ $\left.\lambda_{1}\left(x_{0}\right) \lambda_{2}\left(x_{0}\right) \equiv 1\right]$, but it must be imposed in the general compressible situation of interest here (Beron-Vera et al. 2015). Note that while a material curve satisfying (4) and (5) normally attracts nearby fluid from $t_{0}-T$ to $t_{0}$, it normally repels fluid in the computation direction, $t_{0}$ to $t_{0}-T$. Thus, it is referred to as a squeezeline (Olascoaga et al. 2013).

The above results in a family of LCSs at time $t_{0}$. The subset in that family corresponding to the locally most attracting LCSs is of greatest interest as these LCSs will have the strongest influence on neighboring fluid over the interval $\left[t_{0}-T, t_{0}\right]$. These LCSs locally maximize (5) among nearby LCSs.
The numerical computation of LCSs is well documented and a software tool is available (Onu et al. 2015). In brief, this begins by solving the trajectory equation for a grid of initial conditions spanning the region of interest and over a given time interval. The CauchyGreen tensor is then evaluated using simple center differences over the grid of initial conditions. CauchyGreen squeezelines are finally computed by solving (4) with the right-hand side written as $\operatorname{sign}\left\{\xi_{1}\left[x_{0}(s-\right.\right.$ $\Delta)]\} \xi_{1}\left[x_{0}(s)\right]$, where $\Delta$ is the integration step, which guarantees a unique orientation for $\xi_{1}\left[x_{0}(s)\right]$ [note that $+\xi_{i}\left(x_{0}\right)$ is an eigenvector of $C_{t_{0}}^{t}\left(x_{0}\right)$ as $\left.-\xi_{i}\left(x_{0}\right)\right]$. Here, the width of the computational grid is set at $0.1 \mathrm{~km}$. All integrations were carried out using a step-adapting fourth- or fifth-order Runge-Kutta method with cubic interpolation.

\section{c. Climatological Lagrangian coherent structures}

The cLCS computation, as developed by Duran et al. (2018), involves performing suitable averages in two subsequent steps. In the first step we construct a daily climatological flow. The flow climatology on each day is an average of NEMO surface velocities over the 18-yr simulation. With this flow we construct a series of backward-time Cauchy-Green tensor fields on sliding 7-day time windows. This sets the coherence time scale of the LCS analysis. It can be justified on the basis that a few days to a week is a critical time scale for oil spill response which largely motivates this study. In the second step, the Cauchy-Green tensor is averaged over each month of the climatological year-long record. The cLCSs finally follow as squeezelines of the average of the 12 monthly averaged Cauchy-Green tensors for the annual-averaged computation (Fig. 3) and of the monthly averaged Cauchy-Green tensor fields (Fig. 4). The resulting cLCS topology is the manifestation of persistent Lagrangian transport patterns.

To clarify the meaning of "persistent," as used in this paper, we note that many transport patterns from observations and simulations are compared to cLCSs which, by construction, are persistent structures. Thus, as many tracer advections conform to cLCSs irrespective of their initial time, we denote these transport patterns as persistent. The distinction between transport mechanisms that are either persistent in time or recurrent, as related to cLCSs, is not investigated in this study and is left for future work.

It must be noted that LCSs computed from daily climatological velocities are exactly invariant (material) for the Lagrangian kinematics sustained by these velocities. But the averaging of the Cauchy-Green tensor fields formally destroys this invariance property. However, as we will show below, the invariance 


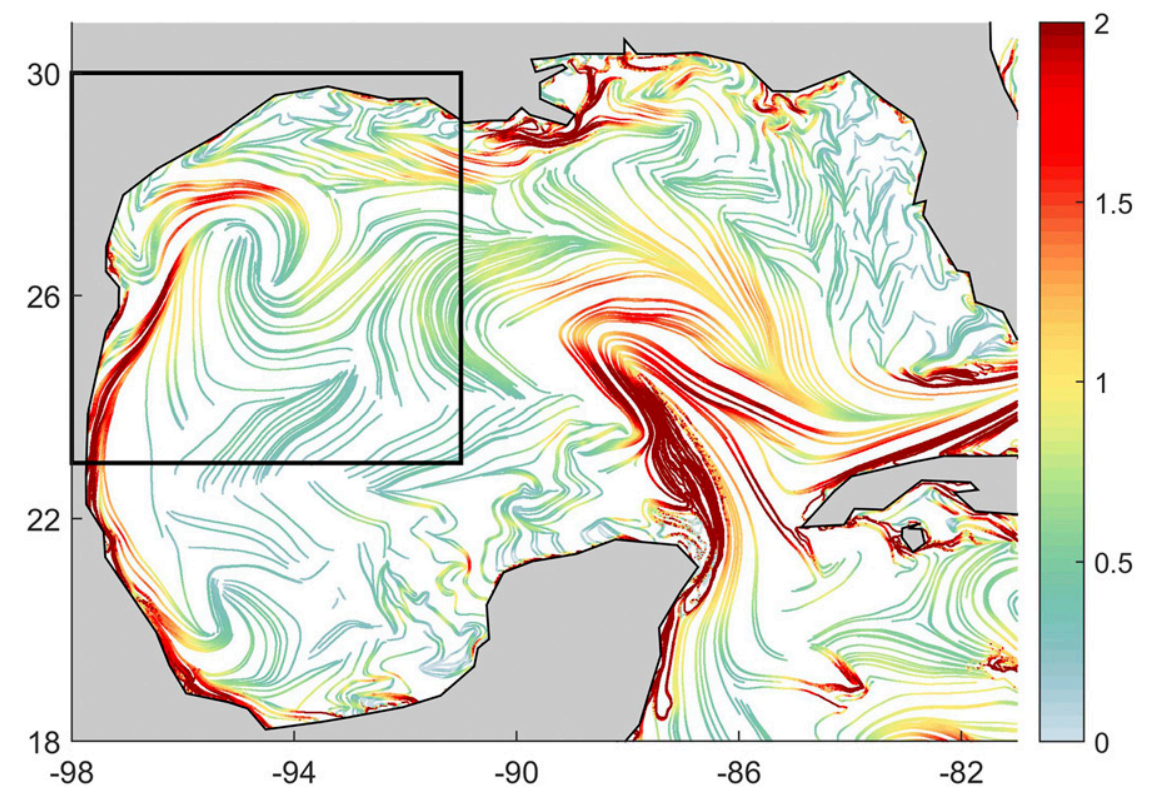

FIG. 3. Annual cLCS map for the GoM. Colors indicate strength of attraction quantified by $\log \sqrt{\lambda_{2}}$. The black box indicates the NWGoM region of interest.

property and their influence on neighboring fluid are to a good extent preserved, not just for the climatological velocities, but also for the instantaneous velocities in an ensemble-mean sense.

\section{d. Drifters}

To assess the significance of the computed cLCSs from the NEMO simulation, independent (quasi) Lagrangian data were employed. These data came from a large collection of satellite-tracked drifter trajectories obtained from multiple studies between 1994 and 2016. A total of 3207 drifter trajectories from several different sources were considered: Grand Lagrangian Experiment (GLAD; Beron-Vera and LaCasce 2016; Olascoaga et al. 2013; Poje et al. 2014), Lagrangian Submesoscale Experiment (LASER), National Oceanic and Atmospheric Administration (NOAA) Global Drifter Program (GDP; Lumpkin and Pazos 2007), Surface Current Lagrangian-Drift Program (SCULP; Ohlmann and Niiler 2005; Sturges et al. 2001), Horizon Marine Inc.'s EddyWatch program, Centro de Investigación Científica y de Educación Superior de EnsenadaPetróleos Mexicanos (CICESE-PEMEX), NOAA South Florida Program (SFP), and the U.S. Coast Guard during LASER. For details regarding the above drifter studies see Miron et al. (2017).

\section{e. Ensemble tracer and drifter densities}

We wish to show that the computed monthly cLCSs from the NEMO climatological velocities shape, to leading order, the evolution of passive tracers under advection by NEMO instantaneous velocities. This is done by comparing the cLCSs with ensemble-mean trajectory evolutions. To scrutinize the influence of the cLCSs on tracer motion over a given month, we integrate trajectories starting every day on the given month along each of the 18 years of the NEMO simulation. We then lay a regular grid (25-km grid spacing) down on the domain of interest and count the number of tracer particles falling inside each bin of the grid. The counting is performed after $n$ days of the trajectory initialization, ignoring the specific year when that happened. The result is a $2 \mathrm{D}$ histogram that provides a discrete representation of the density of the tracers on day $n$. Figures 5 and 6 show tracer densities (normalized by the mean density) computed on days 7, 14, and 28 (left to right) during January, April, July, and October (top to bottom) for tracers initially inside the indicated box. Trends in the influence of annual cLCSs on surface transport over the 18-yr simulation, regardless of season, can be examined in Fig. 7, where combined ensemble tracer densities were computed from the four monthly drifter densities in Figs. 5 and 6 and superimposed onto the annual cLCS map. Similarly, this method is applied to the historical drifter dataset (Fig. 8). For the historical drifter density distributions, the trajectory is initiated at the time when a drifter enters the specified box. Thus, an ensemble of trajectories from the specified boxes is generated from which the drifter density distributions can be computed. It should be noted that the historical 

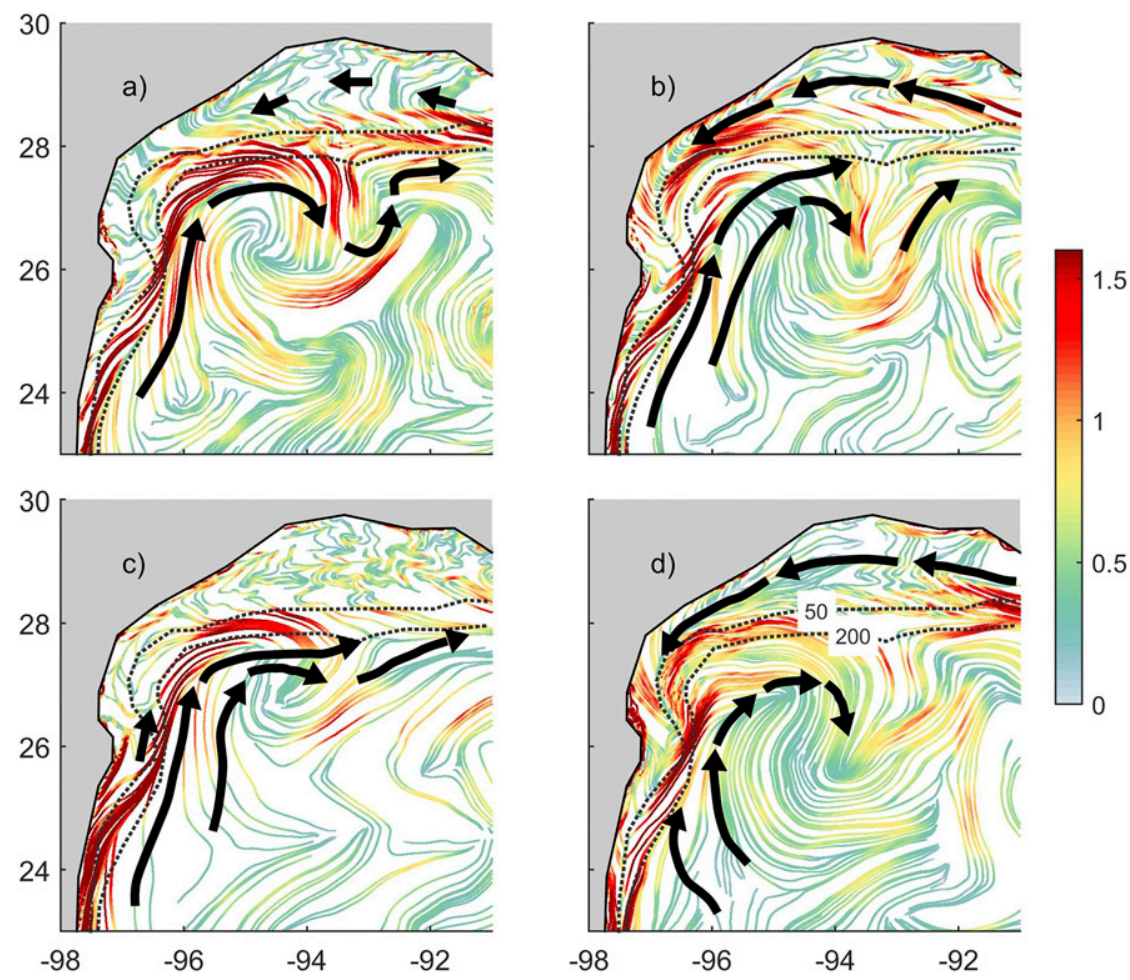

FIG. 4. Monthly cLCSs maps for (a) January, (b) April, (c) July, and (d) October. Colors indicate strength of attraction quantified by $\log \sqrt{\lambda_{2}}$. Black arrows demark notable Eulerian flow patterns. The 50- and 200-m isobaths are demarked by the black dashed lines and are labeled in (d).

drifter data cannot provide the data density of repeated tracer deployments over the 18-yr simulation. Densities computed from the simulation will be referred to as "tracer densities" and densities computed from the historical drifter record will be referred to as "drifter densities." Two boxes are used as the origin of deployed tracers, one over the LaTex shelf and the other just shoreward of the Perdido fold belt region. The tracers and drifters deployed over the LaTex shelf will be referred to as "LaTex" tracers (or drifters) and those deployed in the vicinity of the Perdido fold belt region will be referred to as "Perdido" tracers (or drifters). The locations of the deployment boxes were chosen to highlight the barrier to cross-shore flow along the shelf break, maximize domain residence times of the tracers, and represent locations where there is the potential for oil spills. For each iteration within each month the percentages of the total number of LaTex tracers and drifters that pass offshore through the cLCSs that run along the shelf break and enter the deep ocean are estimated from their respective density distributions (Figs. 5, 8a-d). Likewise, the percentages of Perdido tracers and drifters that pass onshore through the cLCSs that run along the continental shelf break and enter the shelf waters are estimated (Figs. 6, 8e-h).

\section{Results}

Seasonal circulation patterns in the NWGoM, as represented by monthly averaged climatological streamlines determined from the NEMO simulation along with superimposed black arrows that highlight primary flow features (Fig. 2), generally agree with previous studies (Oey 1995; Sturges 1993; Zavala-Hidalgo et al. 2003). NEMO exhibits strong anticyclonic flow offshore of the shelf break with a vortex centered at approximately $26^{\circ} \mathrm{N}$, $94^{\circ} \mathrm{W}$. July exhibited the strongest flow along the MexTex shelf break and flow was not directed southward along the eastern flank of the vortex as exhibited in the other months. Flow over the shelf was generally cyclonic, with the exception of July, and the strongest cyclonic flow over the shelf occurred in April and October.

NEMO exhibits a persistent hook-like mesoscale pattern of strongly attracting cLCSs in the NWGoM, which can be observed in the annual cLCSs (Fig. 3) and monthly cLCSs (Fig. 4). The base of the hook-like pattern extends northward along the MexTex shelf 

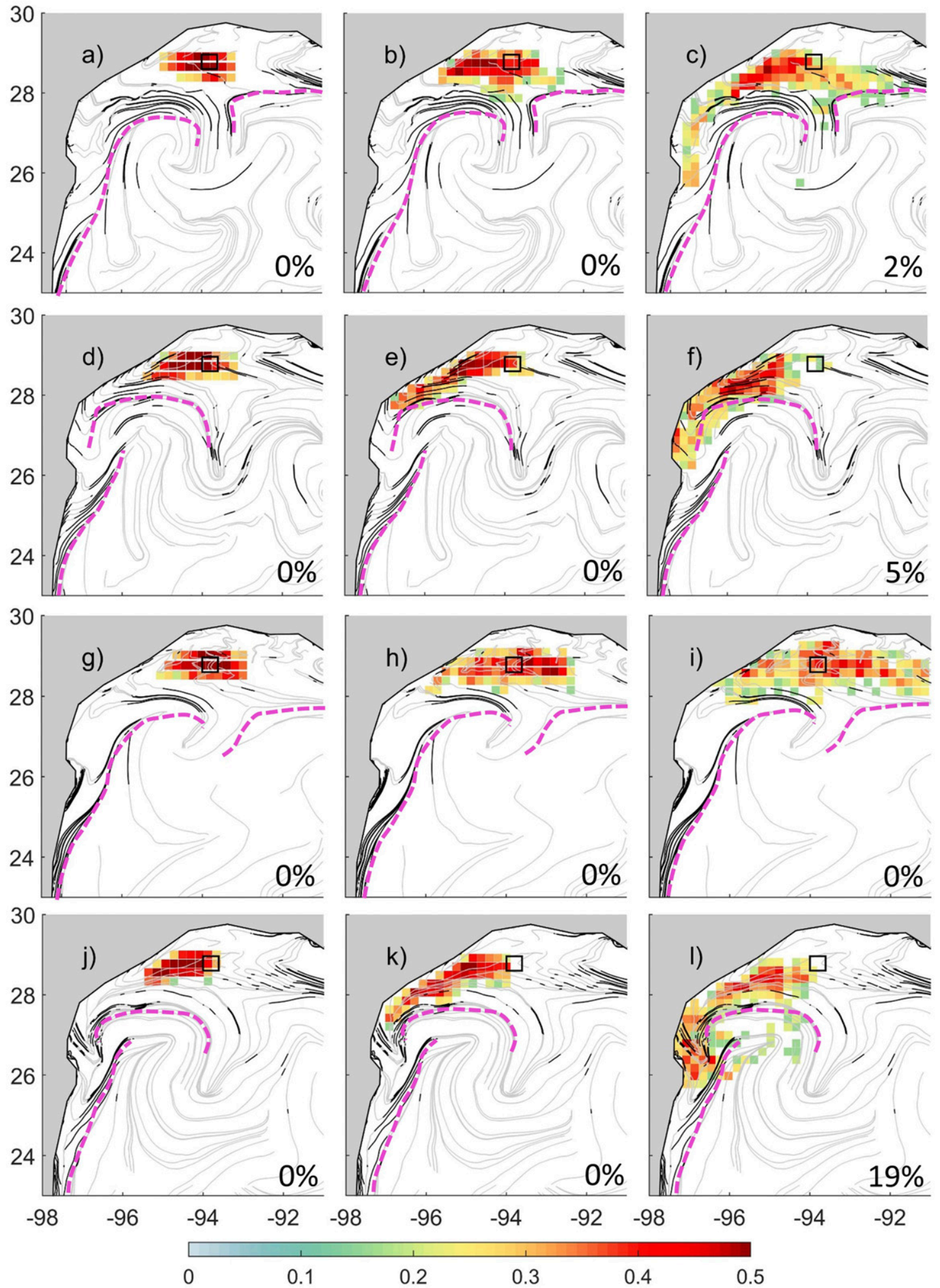

FIG. 5. Ensemble tracer densities from simulated trajectories over the LaTex shelf for days 7, 14, and 28 in (a)-(c) January, (d)-(f) April, (g)-(i) July, and (j)-(l) October. The density has been transformed to the $1 / 4$ power (i.e., $d^{1 / 4}$ ). The underlying monthly cLCS maps correspond to Figs. 2a-d and are gray-scaled according to the strength of attraction quantified by $\log \sqrt{\lambda_{2}}$ : black $(>1.0)$ and gray $(<1.0)$. Black boxes indicate the position of initial tracer deployments on the first of each month. Percentage of tracers that traversed the cLCSs along the shelf break, demarked by the dashed magenta line, are included with each panel. 

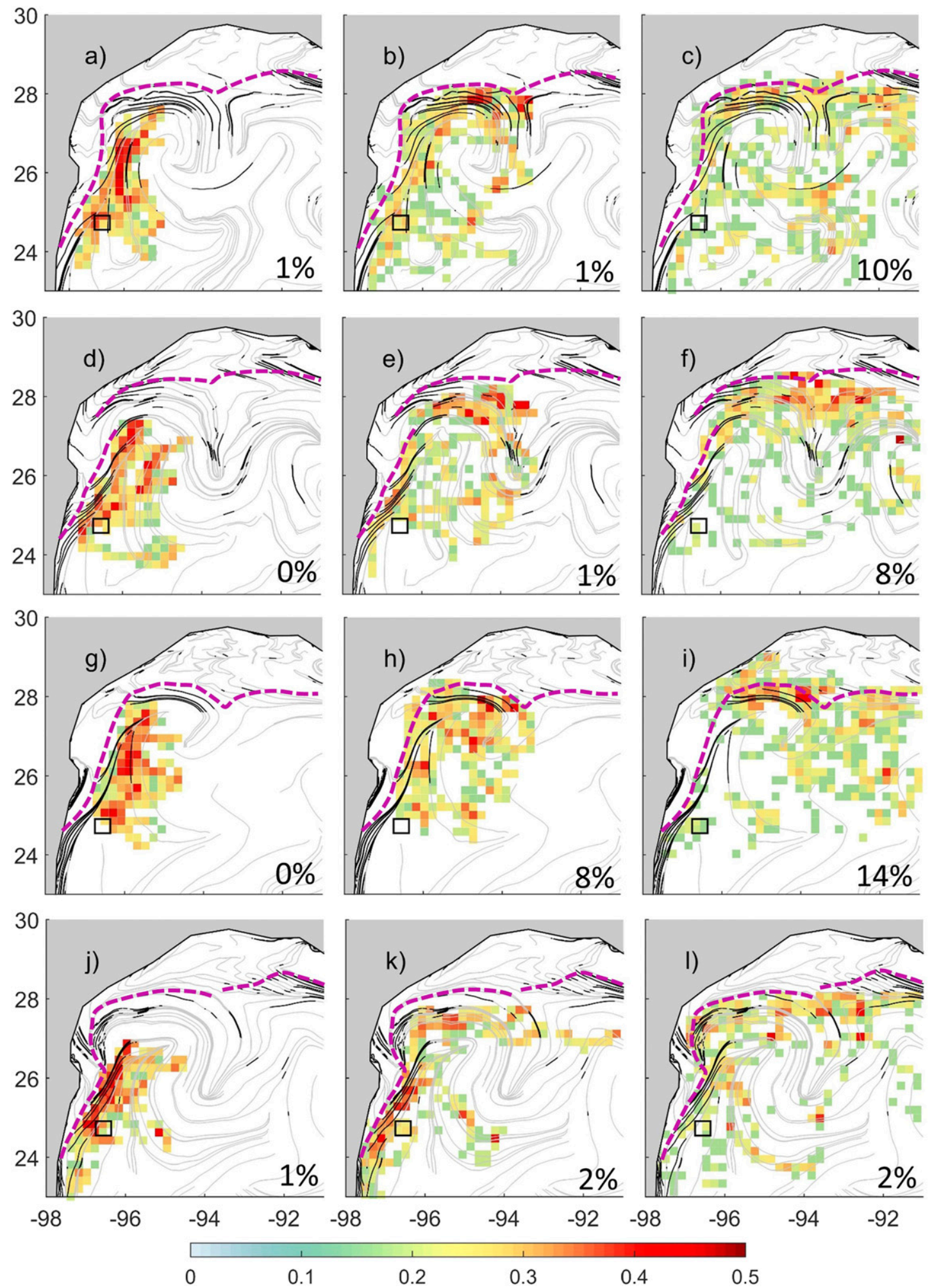

FIG. 6. Ensemble tracer densities from simulated trajectories over the Perdido region for days 7, 14, and 28 in (a)-(c) January, (d)-(f) April, (g)-(i) July, and (j)-(l) October. The density has been transformed to the $1 / 4$ power (i.e., $d^{1 / 4}$ ). The underlying monthly cLCS maps correspond to Figs. 2a-d and are gray-scaled according to the strength of attraction quantified by $\log \sqrt{\lambda_{2}}$ : black $(>1.0)$ and gray $(<1.0)$. Black boxes indicate the position of initial tracer deployments on the first of each month. Percentage of tracers that traversed the cLCSs along the shelf break, demarked by the dashed magenta line, are included with each panel. 

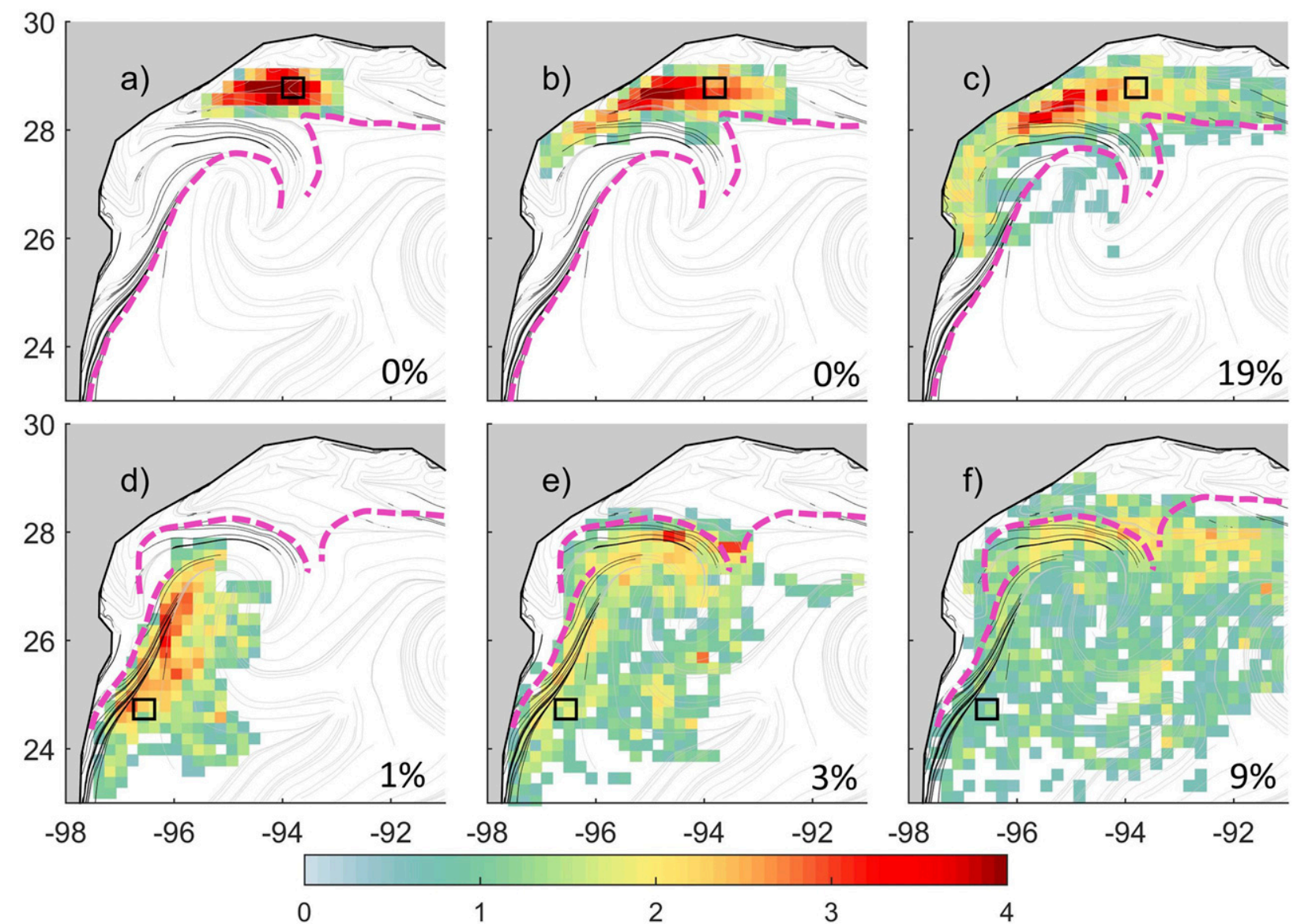

0

2

3

FIG. 7. Combined ensemble tracer densities from simulated trajectories for days 7,14 , and 28 over the (a)-(c) LaTex shelf and (d)-(f) Perdido region. The density has been transformed to the $1 / 3$ power (i.e., $d^{1 / 3}$ ). The underlying annual cLCS map, which corresponds to Fig. 3, is gray-scaled according to strength of attraction quantified by $\log \sqrt{\lambda_{2}}$ : black $(>1.0)$ and gray $(<1.0)$. Black boxes indicate the position of initial tracer deployments on the first of each month. Percentage of tracers that traversed the cLCSs along the shelf break, demarked by the dashed magenta line, are included with each panel.

break demarked by the $50-\mathrm{m}$ isobath and continues to follow the shelf break by curving eastward. The tip of the hook extends southward away from the LaTex shelf break in the vicinity of $94^{\circ} \mathrm{W}$. The hook-like cLCS pattern follows along the shoreward edge of the strong anticyclonic circulation exhibited by NEMO beyond the shelf break (Figs. 1, 2, 4). The meridional position of these cLCSs did not substantively migrate seasonally and is a persistent pattern also observed in the annual cLCSs (Fig. 3). The eastward Eulerian flow indicated by black arrows in Fig. 4 tends to cross the cLCSs that are directed southward, demarking the tip of the hooklike pattern. This is most notable in July (Fig. 4c). The black arrows, however, do not cross the cLCSs when their attraction is strong. Similarly, over the shelf, the cyclonic Eulerian mean flow is observed to cross weakly attracting cLCSs and run parallel to strongly attracting cLCSs. This is most notable in April and October, where strongly attracting cLCSs extend along the southern flank of strong narrow cyclonic flow where the shelf break begins to curve southward at the western extent of the LaTex shelf.

Tracer densities indicate that, in general, the hooklike cLCS pattern represents a boundary that prevents surface transport over the shelf from escaping to the deep ocean (Figs. 5, 7a-c) and represents an initially attracting boundary for circulation immediately offshore of the shelf break (Figs. 6, 7d-f). The resilient cLCS hook therefore represents a transport barrier that isolates the LaTex shelf similar to findings over the west Florida shelf (Olascoaga 2010). The southward pointing tip of the hook-like pattern represents a possible offshore transport route for tracers near the middle of the LaTex shelf break (Figs. 5c, 6b), which is consistent with previous studies (Duran et al. 2018; Martínez-López and Zavala-Hidalgo 2009; Zhang and Hetland 2012). East of the hook-like pattern, along the eastern half of the LaTex shelf break, groups of cLCSs 

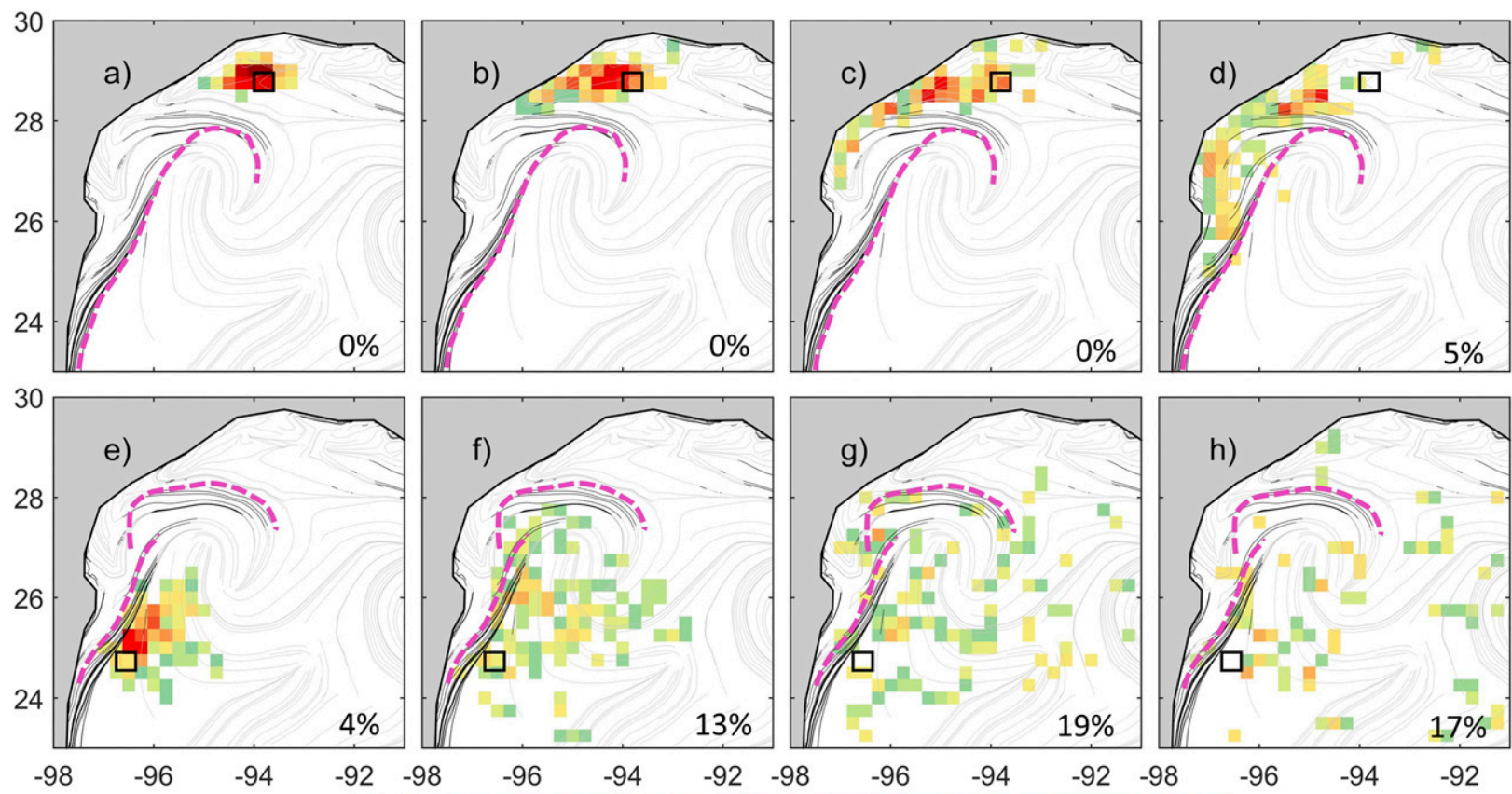

0

2.5

5

7.5

FIG. 8. Historical drifter density distributions for days 3, 7, 14, and 28 from the time drifter trajectories passed through boxes over the (a)-(d) LaTex shelf and (e)-(h) Perdido region. The density has been transformed to the $1 / 3$ power (i.e., $d^{1 / 3}$ ). The underlying annual cLCSs map, which corresponds to Fig. 3 , is gray-scaled according to strength of attraction quantified by $\log \sqrt{\lambda_{2}}$ : black $(>1.0)$ and gray $(<1.0)$. Percentage of drifters that traversed the cLCSs along the shelf break, demarked by the dashed magenta line, are included with each panel.

composed of relatively short sections of strong attraction represent a region of general attraction (Figs. $6 \mathrm{c}, \mathrm{f}, 1$ and 7f). Tracers released on the shelf sufficiently away from the shelf break will not experience attraction by these cLCSs (Figs. 5, 7a-c). Rather, they tend to spread westward over the shelf following the bend in the mostly weak cLCSs there.

Seasonal trends in the transport of tracers over the shelf are consistent with the cLCS topology where westward bends in the cLCSs indicate westward transport in January, April, and October (Figs. 4a,b,d, 5). The convoluted cLCSs over the shelf in July do not indicate transport directionality which is corroborated by the more evenly distributed tracers to the east and west (Figs. 4c, $5 \mathrm{~g}-\mathrm{i})$. One exception to the cLCS barrier along the shelf break to tracers originating over the shelf occurs on 28 January when small amounts (approximately 2\%) of tracers are transported offshore (southward) guided by the southward-pointing tip of the hook-like pattern (Fig. 5c). Another exception occurs on 28 October when approximately $5 \%$ of the tracers extend southward along the MexTex shelf and begin to be flushed out through a gap in the cLCS hook (Fig. 51). That the 28-day advection conforms closely to the cLCSs, which are computed from a 7-day integration period, supports that persistent transport patterns have been determined. However, the observed trapping of tracers over the shelf by processes related to the hook-like cLCSs for time periods of up to 28 days is remarkable considering the cLCS integration period is only 7 days.

The Perdido fold belt is a deep-water geological formation that is known to have great oil exploration potential. What would be the fate of oil in the unforeseen event of a spill? To further explore the significance of the computed cLCSs, and at the same time approximately address this question, we consider the ensemble-mean evolution of tracers initially inside a small box chosen in the vicinity of the Perdido fold belt. For these tracers the rate of dispersion was much greater than those deployed over the LaTex shelf, which is represented by the widely displaced and low tracer densities in the days after their deployment (Figs. 6, 7d-f). Additionally, these tracers were more likely to traverse the hook-like cLCSs onto the shelf. In all four months, tracers initially migrate northward and collect along the strongly attracting southern portion of the hook-like cLCSs on day 7 (Figs. 6a,d,g,j). By day 14 the tracer densities decrease as they become more widely dispersed and there is a tendency for densities to increase along the western LaTex shelf break, which is 
also along the northern portion of the hook-like cLCS (Fig. 7e). At this time the percentages of tracers that traverse the cLCSs and impinge upon the shelf for the four months remain relatively small (Figs. 6b,d,h,k). By day 28 the tracers continue to be dispersed and there is a tendency for them to accumulate along the eastern LaTex shelf break (Fig. 7f), where cLCSs tend to exhibit sections of increased attraction (e.g., Fig. 4a). At this time the percentages of tracers that traverse the cLCSs and impinge upon the shelf for each of the four months are $10 \%, 8 \%, 14 \%$, and $2 \%$ (Figs. $6 \mathrm{c}, \mathrm{f}, \mathrm{i}, 1)$. The Perdido tracers are likely dispersed by the western boundary current along with mesoscale eddies that have originally shed off the Loop Current and migrated westward into the NWGoM. Drifters from the Perdido region were more likely than those deployed over the LaTex shelf to leak shoreward through gaps in the hook-like cLCSs, which was particularly evident in July (Figs. 6g-i).

The aspects just described by the NEMO-simulated Lagrangian circulation are robust to the extent that they generally hold independent of the season, as revealed in Fig. 7, which shows annual cLCSs and the evolution of ensemble-mean annual tracer densities. Overall, the percentage of LaTex tracers that traversed cLCSs along the shelf break after 28 days is approximately $6.5 \%$. For the Perdido tracers traversing shoreward across the cLCSs along the shelf break after 28 days the percentage is approximately $8.5 \%$. The NEMO-simulated cLCSs are not only significant for the NEMO-simulated Lagrangian circulation but, quite remarkably, also to a large extent for the observed Lagrangian circulation. This is demonstrated in Fig. 8, which exhibits similar drifter density distributions to those in Fig. 7, but for densities constructed using historical satellite-tracked drifter trajectory data. The percentages of Perdido drifters that traverse the cLCSs along the shelf break after 3, 7, 14, and 28 days are $3.6 \%, 13.4 \%, 18.6 \%$, and $16.6 \%$ (Fig. 8 ). Only $5 \%$ of the LaTex drifters traverse the shelf break cLCSs after 28 days. There are fewer observed trajectories than simulated trajectories, so it is not possible to achieve a similar level of resolution, but still the agreement with the cLCSs is quite evident.

\section{Discussion}

The presented results clearly illustrate the influence of cLCSs on persistent surface transport patterns in the NWGoM with comparisons of cLCS topology with tracer and drifter density distributions. The interpretation of cLCSs and how they apply to determining surface transport will now be discussed. It should be noted that many of the Lagrangian transport aspects found to be related to cLCS topology are not easily determined from inspection of climatological streamline plots (Fig. 2) or other Eulerian-type analyses such as plots of mean flow or divergence. For example, the abruptness and strength of the attracting hook-like barrier, as previously identified by the cLCSs (Figs. 7d,e), is not easily determined from the climatological streamline plots. Neither can the region of general attraction along the LaTex shelf break (Fig. 7f) and the barrier along the LaTex inner shelf westward flow in April and October (Figs. 4a,d). However, cLCSs cannot identify flow direction, velocity, and shear. The value of cLCS analysis is therefore enhanced when applied in combination with other types of analysis methods.

The entire region along the MexTex and LaTex shelf breaks is prone to baroclinic instabilities due to shear along the shoreward side of the western boundary current and a salinity front that typically follows along the shelf break (Luo et al. 2016; Zavala-Hidalgo et al. 2003). The instabilities are frequently exhibited in the Nemo simulations (Fig. 9), are easily observed with satellite imagery, and occur at spatial scales much smaller than the scales demonstrated by the smooth cLCSs that extend northwestward along the MexTex shelf break (Fig. 4). These structured cLCSs are therefore presumably capturing processes associated with straining of the ocean's surface by mesoscale circulation such as the persistent western boundary current and/or Loop Current eddies. It is not surprising that the cLCSs do not capture the smallspatial-scale and fast-time-scale instabilities due to the temporal averaging used in their calculation. However, it is surprising that there is not more leakage across these cLCSs due to these unresolved instabilities since time-dependent perturbations on a steady jet generically promote transport across the jet (Samelson and Wiggins 2006). This result is consistent with earlier analyses of observed and simulated trajectories using altimetry-derived and high-resolution $(1 \mathrm{~km})$ model velocities, indicating that the mesoscale circulation plays a leading role in shaping transport and mixing in the GoM (Beron-Vera and LaCasce 2016; Olascoaga et al. 2013).

Although Lagrangian circulation associated with the hook-like cLCS generally holds independently of season (Fig. 7), there are notable seasonal trends captured by the cLCS topology. In April and October the hook-like cLCS exhibits a secondary attracting barrier, shoreward of the primary hook-like cLCS, along the 50-m isobath where the continental shelf curves westward at approximately $27.5^{\circ} \mathrm{N}, 96.5^{\circ} \mathrm{W}$ (Figs. $4 \mathrm{~b}, \mathrm{~d}$ ). During these months the longshore component of the winds over the LaTex shelf is westward and drives westward 

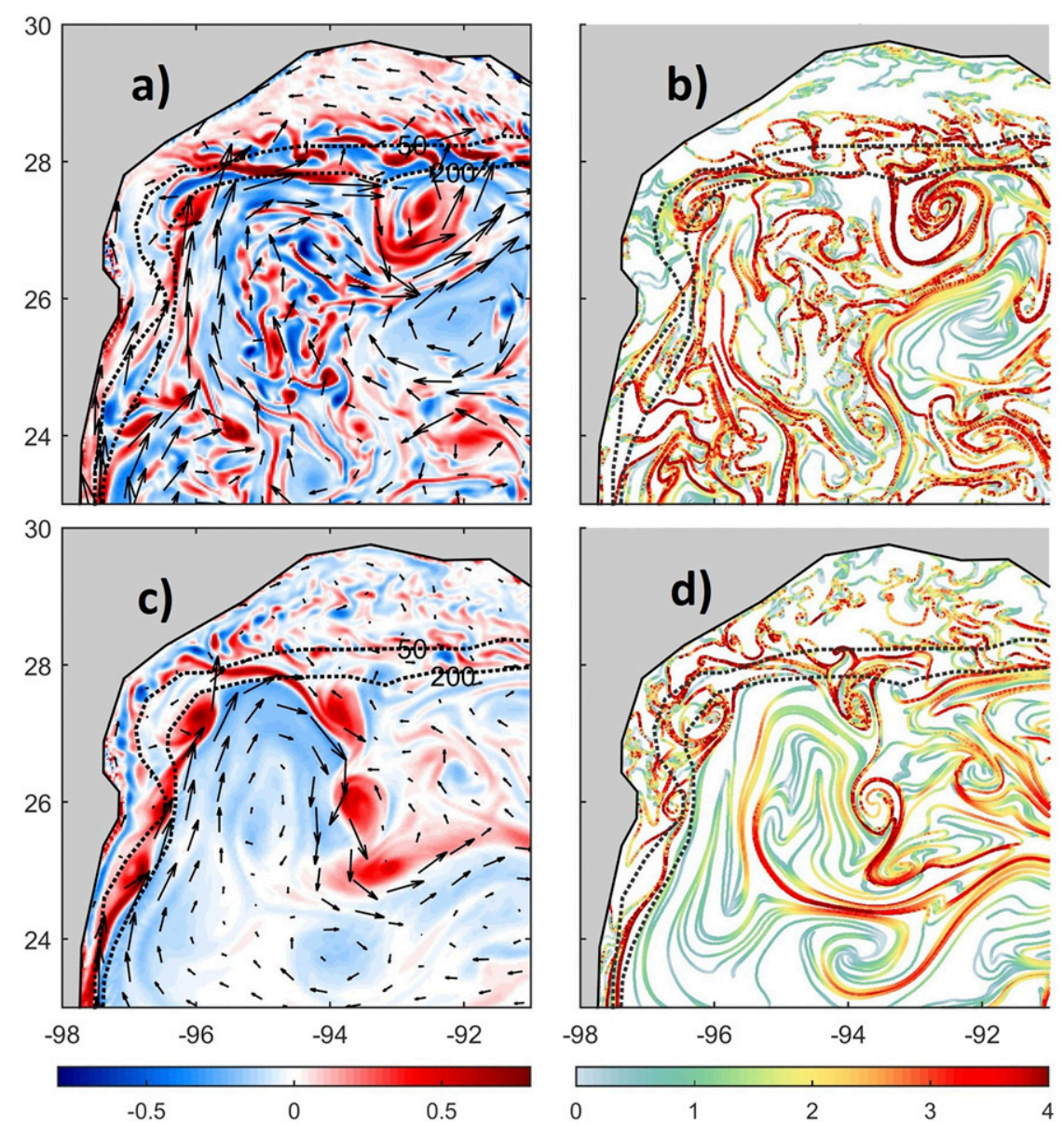

FIG. 9. Daily snapshots of relative vorticity normalized by the Coriolis frequency $(\zeta / f)$ on (a) 3 Jan and (c) 13 Jul 2001, and corresponding daily snapshots of LCSs on (b) 3 Jan and (d) 13 Jul 2001 computed from the NEMO simulation. Strength of LCS attraction is quantified by $\log \sqrt{\lambda_{2}}$. The 50- and 200-m isobaths are demarked by the black dashed lines and are labeled in (a) and (c).

flow (Zavala-Hidalgo et al. 2003) consistent with Figs. $2 b$ and $2 d$. This secondary attracting barrier in April and October forms along the 50-m isobath, which is along the offshore edge of the westward flow along the inner LaTex shelf and acts as cross-shelf barrier to the Perdido tracers (Figs. 6e,f,k,l) and the LaTex tracers (Figs. 5e,f,k,l). Cross-shelf exchange at the northwest corner of the NWGoM is therefore hindered by two cLCS barriers during these months. The most notable cross-shelf exchange occurred in July as demonstrated by the leakage of the Perdido tracers across the hook-like cLCS and onto the inner shelf (Figs. 6h,i). Predominant wind forcing is from the southeast during July, which drives a relatively weak northward flow over the MexTex shelf and does not contribute to flow over the LaTex shelf. During July there is no westward flow over the LaTex shelf, and there is no secondary attracting barrier along this flow as exhibited in April and October. There is therefore no secondary barrier to block the tracers, and there is no cyclonic flow over the shelf to counter onshore migration of the tracers at the northwest corner of the NWGoM.

The cLCS patterns along the eastern half of the LaTex shelf break, east of the hook-like cLCS, tend to exhibit shorter sections of strong attraction than those associated with the hook-like feature (Fig. 4). Mean flow here is weaker than the hook-like flow, which presumably allows smaller-scale (including submesoscale) straining and confluence to notably contribute to surface transport. The cLCSs in this region are therefore likely identifying repeated small-scale and/or submesoscale straining despite the averaging in the cLCS computation. The cumulative effect of these cLCSs is the identification of a less-defined attracting barrier for surface transport which is best represented by the increase in 
tracer densities along the eastern LaTex shelf break (Fig. 7f). July exhibited the weakest cLCS attraction in this region, which is corroborated by the lack of defined attraction of Perdido tracers (Fig. 6i) in comparison to the other months and lack of attraction of LaTex tracers that migrated eastward (Fig. 5i). The strongestattracting cLCSs along the eastern LaTex shelf break occurred in January, which is consistent with increased submesoscale energy due to a wintertime deepening of the surface mixed layer (Luo et al. 2016). January did not exhibit notably greater Perdido tracer densities along the eastern LaTex shelf break in comparison with April and October despite the strongly attracting cLCSs. This is because many of the tracers had already been guided southward by the hook-like circulation on day 14 (Fig. 6b). However, the LaTex tracers that migrated eastward in January are attracted to the cLCSs along the shelf break (Fig. 5c) in comparison to the July tracers that migrated eastward over the shelf (Fig. 5i). In general, and similar to the behavior of surface transport associated with the hook-like cLCSs, the cLCSs along the eastern LaTex shelf break behave as an attracting barrier to surface material originating offshore of the shelf break.

Weak cLCSs did not consistently represent processes that strongly influence simulated tracer behavior, although there are a few instances when groups of weak cLCSs can be corroborated with tracer densities. Groups of weak cLCSs could be the result of persistent weak LCS occurrence or spurious strong LCS events that are captured in the averaging of their computations. The weak cLCSs over the deep ocean in the NWGoM are due to averaging in a region of high surface circulation variability related, in part, to the influence of migrating Loop Current eddies. Groups of relatively weak cLCSs appear to be identifying the offshore guidance of tracers between $26^{\circ}$ and $24^{\circ} \mathrm{N}$ in early January (Fig. 6a) and in October (Figs. 6j-1). Although our focus is on circulation over the shelf and along the shelf break where results can be verified with tracer and drifter densities, the long smooth weak cLCSs over the deep ocean suggest that mesoscale processes are the primary drivers of surface transport like the influence of mesoscale surface transport associated with the hook-like cLCSs.

The notably convoluted cLCS topology over the LaTex shelf in July (Fig. 4c) is worth addressing. The climatological flow during July is very weak. Additionally, there is a shallow mixed layer due to relatively weaker wind forcing and freshwater discharge extending over the shelf which will constrict the spatial scales of submesoscale processes. Without persistent straining of the ocean surface by the mean flow, the cLCSs in July over the LaTex shelf are speculated to be the result of the climatological averaging of submesoscale processes. Repeatedly observed convoluted LCSs over the shelf, exemplified in Fig. 9d, are consistent with the secondary summertime peak in submesoscale activity observed by Luo et al. (2016), which was attributed to river discharge and associated lateral density gradients. This is a topic left for future studies.

The direct applicability of cLCSs for predicting surface pollution transport is highlighted with the comparisons of tracer and drifter densities to the cLCSs. Of particular interest is the destination of potential oil spills over the Perdido fold belt region and the destination of surface pollution, harmful algal blooms, and oil spills originating over the LaTex shelf (Thyng et al. 2013). Tracer densities indicate that if an oil spill were to occur at the box in the vicinity of the Perdido region there would likely be initial accumulation of surface oil along the hook-like cLCS pattern at the shelf break but no leakage across the shelf break for up to 28 days (Fig. 6) with the exception of during the summer (represented by July) when some leakage over the shelf occurs after 14 days (Fig. 6h). Actual drifters indicate that the hook-like cLCS pattern acts as an attracting barrier for up to approximately 7 days before leakage occurs across the shelf break (Fig. 8), although there is not sufficient drifter data to determine seasonal trends. Surface pollution originating over the LaTex shelf, based on the behavior of both tracer and drifter densities, would be expected to remain trapped over the shelf for up to 28 days and that there would not be an accumulation of these pollutants along the shelf break as the hook-like cLCS behaves as a barrier but not an attracting barrier for shelf circulation.

\section{Summary and conclusions}

We have extracted persistent Lagrangian transport patterns by computing climatological Lagrangian coherent structures, or cLCSs, from an 18-yr simulation of surface current velocities in the Gulf of Mexico (GoM). The simulation was performed by an implementation of the submesoscale-permitting free-running Nucleus for European Modelling of the Ocean (NEMO). First, we averaged the velocity record to construct daily climatological velocities. Second, we performed monthly and annual averages of the Cauchy-Green tensor computed in backward time over sliding windows along a climatological year to construct monthly and annual attracting cLCSs maps. Attention was placed on the northwestern GoM mainly because of the importance of understanding Lagrangian transport and pollutant dispersion in a region where deep-water oil exploration is very important, and because NEMO exhibits a persistent hook-like cLCS 
pattern associated with a strong anticyclonic western boundary current and the decay of Loop Current eddies. The hook-like cLCSs were found to persist nearly yearround, identified mesoscale patterns in surface transport, and identified a surface transport barrier that isolates the continental shelf from circulation beyond the shelf break. This isolation, and hence the significance of the cLCSs, was verified with ensemble-mean Lagrangian trajectories generated numerically by the NEMO simulation as well as observed with historical satellite-tracked surface drifting buoys. The significance of the mesoscale cLCSs is quite surprising given the intense submesoscale activity sustained by NEMO. Exceptions to the dominant influence of mesoscale processes on Lagrangian transport occur along the eastern portion of the LaTex shelf break where mean flow decreases and relatively short sections of strongly attracting cLCSs identify a region of general attraction. The percentage of tracers and drifters originating from a box over the LaTex shelf that traversed the cLCSs along the shelf break into the deep ocean after 28 days was estimated to be $19 \%$ and $5 \%$. The percentage of tracers and drifters originating from a box just beyond the MexTex shelf break that traversed the cLCSs along the shelf break onto the shelf after 28 days was estimated to be $19 \%$ and $17 \%$. In summary, simulations and observations both indicate that the continental shelf is difficult to be reached by pollutants originating from sources beyond the shelf break but can be heavily impacted by pollutants released over the shelf.

Acknowledgments. The thoughtful suggestions and comments from two anonymous reviewers are greatly appreciated. We thank Favio Medrano from the Departamento de Computación at CICESE for his help in speeding up the LCS computations. We would also like to thank Alejandro Domínguez (CICESE) for his input and conversations. The GLAD (doi:10.7266/N7VD6WC8) and LASER (doi:10.7266/N7W0940J) drifter trajectory datasets are publicly available through the Gulf of Mexico Research Initiative Information and Data Cooperative (GRIIDC) at https://data.gulfresearchinitiative.org. The NOAA/GDP dataset is available at http://www.aoml.noaa. gov/phod/dac. The drifter trajectory data from Horizon Marine Inc.'s EddyWatch program have been obtained as a part of a data exchange agreement between Horizon Marine Inc. and CICESE-Pemex. The CICESE-Pemex "Caracterización Metoceánica del Golfo de México" project was funded by PEMEX contracts SAP-428217896, 428218855 , and 428229851 . The quality control and postprocessing of the CICESE-Pemex data were carried out by Paula Garcia and Argelia Ronquillo. Support for this work was provided by Consejo Nacional de Ciencia y
Tecnología (CONACyT)-Secretaría de Energía (SENER) Grant 201441 (MKG, FJBV, MJO, JS, and JJ) as part of the Consorcio de Investigación del Golfo de México (CIGoM) and the Gulf of Mexico Research Initiative (FJBV and MJO) as part of the Consortium for Advanced Research of Transport of Hydrocarbons in the Environment (CARTHE). Work by RD was in support of the National Energy Technology Laboratory's ongoing research under the Offshore Field Work Proposal DOE NETL FY14-17 under the RES contract DE-FE0004000.

\section{REFERENCES}

Beron-Vera, F. J., and J. H. LaCasce, 2016: Statistics of simulated and observed pair separations in the Gulf of Mexico. J. Phys. Oceanogr., 46, 2183-2199, https://doi.org/10.1175/ JPO-D-15-0127.1.

— M. J. Olascoaga, G. Haller, M. Farazmand, J. Triñanes, and Y. Wang, 2015: Dissipative inertial transport patterns near coherent Lagrangian eddies in the ocean. Chaos, 25, 087412, https://doi.org/10.1063/1.4928693.

Chu, P. P., L. M. Ivanov, and O. V. Melnichenko, 2005: Fall-winter current reversals on the Texas-Louisiana continental shelf. J. Phys. Oceanogr., 35, 902-910, https://doi.org/10.1175/JPO2703.1.

Dai, A., and K. E. Trenberth, 2002: Estimates of freshwater discharge from continents: Latitudinal and seasonal variations. J. Hydrometeor., 3, 660-687, https://doi.org/10.1175/ 1525-7541(2002)003<0660:EOFDFC $>2.0 . C O ; 2$.

Duran, R., F. J. Beron-Vera, and M. J. Olascoaga, 2018: Extracting quasi-steady Lagrangian transport patterns from the ocean circulation: An application to the Gulf of Mexico. Sci. Rep., $\mathbf{8}$, 5218, https://doi.org/10.1038/s41598-018-23121-y.

Dussin, R., B. Barnier, L. Brodeau, and J. M. Molines, 2016: The making of Drakkar forcing set DFS5. DRAKKAR/MyOcean Rep. 01-04-16, 34 pp., https://www.drakkar-ocean.eu/publications/ reports/report_DFS5v3_April2016.pdf.

Farazmand, M., D. Blazevski, and G. Haller, 2014: Shearless transport barriers in unsteady two-dimensional flows and maps. Physica D, 278-279, 44-57, https://doi.org/10.1016/ j.physd.2014.03.008.

Gough, M. K., A. Reniers, M. J. Olascoaga, B. K. Haus, J. MacMahan, J. Paduan, and C. Halle, 2016: Lagrangian Coherent Structures in a coastal upwelling environment. Cont. Shelf Res., 128, 36-50, https://doi.org/10.1016/j.csr.2016.09.007.

Hall, C. A., and R. R. Leben, 2016: Observational evidence of seasonality in the timing of loop current eddy separation. Dyn. Atmos. Oceans, 76, 240-267, https://doi.org/10.1016/ j.dynatmoce.2016.06.002.

Haller, G., 2011: A variational theory of hyperbolic Lagrangian coherent structures. Physica D, 240, 574-598, https://doi.org/ 10.1016/j.physd.2010.11.010.

, 2015: Lagrangian coherent structures. Annu. Rev. Fluid Mech., 47, 137-162, https://doi.org/10.1146/annurev-fluid-010313-141322. , and F. J. Beron-Vera, 2012: Geodesic theory of transport barriers in two-dimensional flows. Physica D, 241, 1680-1702, https://doi.org/10.1016/j.physd.2012.06.012.

Hamilton, P., G. S. Fargion, and D. C. Biggs, 1999: Loop current eddy paths in the western Gulf of Mexico. J. Phys. Oceanogr., 29, 1180-1207, https://doi.org/10.1175/1520-0485(1999)029<1180: LCEPIT > 2.0.CO;2. 
— T. J. Berger, and W. Johnson, 2002: On the structure and motions of cyclones in the northern Gulf of Mexico. J. Geophys. Res., 107, 3208, https://doi.org/10.1029/1999JC000270.

Jouanno, J., J. Ochoa, E. Pallàs-Sanz, J. Sheinbaum, F. AndradeCanto, J. Candela, and J.-M. Molines, 2016: Loop current frontal eddies: Formation along the Campeche Bank and impact of coastally trapped waves. J. Phys. Oceanogr., 46, 3339-3363, https://doi.org/10.1175/JPO-D-16-0052.1.

Leben, R. R., 2005: Altimeter-derived Loop Current metrics. Circulation in the Gulf of Mexico: Observations and Models, Geophys. Monogr., Vol. 161, Amer. Geophys. Union, 181-201.

Lumpkin, R., and M. Pazos, 2007: Measuring surface currents with Surface Velocity Program drifters: The instrument, its data, and some recent results. Lagrangian Analysis and Prediction of Coastal and Ocean Dynamics, Cambridge University Press, 39-67.

Luo, H., A. Bracco, Y. Cardona, and J. C. McWilliams, 2016: Submesoscale circulation in the northern Gulf of Mexico: Surface processes and the impact of the freshwater river input. Ocean Modell., 101, 68-82, https://doi.org/10.1016/ j.ocemod.2016.03.003.

Madec, G., and the NEMO Team, 2016: NEMO ocean engine. Note du Pole de modélisation de l'Institut Pierre-Simon Laplace 27, 386 pp., https:/www.nemo-ocean.eu/wp-content/uploads/ NEMO_book.pdf.

Martínez-López, B., and J. Zavala-Hidalgo, 2009: Seasonal and interannual variability of cross-shelf transports of chlorophyll in the Gulf of Mexico. J. Mar. Syst., 77, 1-20, https://doi.org/ 10.1016/j.jmarsys.2008.10.002.

Miron, P., F. J. Beron-Vera, M. J. Olascoaga, J. Sheinbaum, P. Pérez-Brunius, and G. Froyland, 2017: Lagrangian dynamical geography of the Gulf of Mexico. Sci. Rep., 7, 7021, https://doi.org/10.1038/s41598-017-07177-w.

Morey, S. L., J. Zavala-Hidalgo, and J. J. O'Brien, 2005: The seasonal variability of continental shelf circulation in the northern and western Gulf of Mexico from a high-resolution numerical model. Circulation in the Gulf of Mexico: Observations and Models, Geophys. Monogr., Vol. 161, Amer. Geophys. Union, 203-218.

Oey, L.-Y., 1995: Eddy- and wind-forced shelf circulation. J. Geophys. Res., 100, 8621-8637, https://doi.org/10.1029/ 95JC00785.

Ohlmann, J. C., and P. P. Niiler, 2005: Circulation over the continental shelf in the northern Gulf of Mexico. Prog. Oceanogr., 64, 45-81, https://doi.org/10.1016/ j.pocean.2005.02.001.

Olascoaga, M. J., 2010: Isolation on the West Florida Shelf with implications for red tides and pollutant dispersal in the Gulf of Mexico. Nonlinear Processes Geophys., 17, 685-696, https:// doi.org/10.5194/npg-17-685-2010.
, and G. Haller, 2012: Forecasting sudden changes in environmental pollution patterns. Proc. Natl. Acad. Sci. USA, 109, 4738-4743, https://doi.org/10.1073/pnas.1118574109.

- and Coauthors, 2013: Drifter motion in the Gulf of Mexico constrained by altimetric Lagrangian coherent structures. Geophys. Res. Lett., 40, 6171-6175, https://doi.org/10.1002/ 2013 GL058624.

Onu, K., F. Huhn, and G. Haller, 2015: LCS Tool: A computational platform for Lagrangian coherent structures. J. Comput. Sci., 7, 26-36, https://doi.org/10.1016/j.jocs.2014.12.002.

Poje, A. C., and Coauthors, 2014: Submesoscale dispersion in the vicinity of the Deepwater Horizon spill. Proc. Natl. Acad. Sci. USA, 111, 12 693-12 698, https://doi.org/10.1073/ pnas. 1402452111.

Samelson, R. M., and S. Wiggins, 2006: Lagrangian Transport in Geophysical Jets and Waves. Interdisciplinary Applied Mathematics, Vol. 31, Springer, 150 pp.

Sandery, P. A., and P. Sakov, 2017: Ocean forecasting of mesoscale features can deteriorate by increasing model resolution towards the submesoscale. Nat. Commun., 8, 1566, https:// doi.org/10.1038/s41467-017-01595-0.

Sturges, W., 1993: The annual cycle of the western boundary current in the Gulf of Mexico. J. Geophys. Res., 98, 18 053-18 068, https://doi.org/10.1029/93JC01730.

— Loop Current in the Gulf of Mexico: A revised estimate. J. Phys. Oceanogr., 30, 1814-1819, https://doi.org/10.1175/ 1520-0485(2000)030<1814:FORSFT >2.0.CO;2.

— P. Pearn, P. P. Niiler, and R. H. Weisberg, 2001: Northeastern Gulf of Mexico inner shelf circulation study. OCS Rep. MMS 2001-103, 90 pp., https://www.boem.gov/ESPIS/3/3216.pdf .

Sutyrin, G. G., G. D. Rowe, L. M. Rothstein, and I. Ginis, 2003: Baroclinic eddy interactions with continental slopes and shelves. J. Phys. Oceanogr., 33, 283-291, https://doi.org/ 10.1175/1520-0485(2003)033<0283:BEIWCS >2.0.CO;2.

Thyng, K. M., R. D. Hetland, M. T. Ogle, X. Zhang, F. Chen, and L. Campbell, 2013: Origins of Karenia brevis harmful algal blooms along the Texas coast. Limnol. Oceanogr. Fluids Environ., 3, 269-278, https://doi.org/10.1215/21573689-2417719.

Vukovich, F. M., and B. W. Crissman, 1986: Aspects of warm rings in the Gulf of Mexico. J. Geophys. Res., 91, 2645-2660, https:// doi.org/10.1029/JC091iC02p02645.

Zavala-Hidalgo, J., S. L. Morey, and J. J. O'Brien, 2003: Seasonal circulation on the western shelf of the Gulf of Mexico using a high-resolution numerical model. J. Geophys. Res., 108, 3389, https://doi.org/10.1029/2003JC001879.

Zhang, Z., and R. Hetland, 2012: A numerical study on convergence of alongshore flows over the Texas-Louisiana shelf. J. Geophys. Res., 117, C11010, https://doi.org/10.1029/ 2012JC008145. 